\title{
ALIMENTOS TRANSGÊNICOS: PERCEPÇÃO E ACEITABILIDADE DA POPULAÇÃO TOCANTINENSE
}

Transgenic Food: perception and acceptability by the population of Tocantins

Alimentos transgênicos: percepción y aceptabilidad de población de Tocantins

Desafios

Artigo Original

Original Article

Artículo Original

\section{Bárbara Marques Bianchini Condessa ${ }^{1}$, Isabela Marinho Menezes ${ }^{2}$, Mirelle Ribeiro Araújo ${ }^{1}$, Alex Fernando de Almeida ${ }^{1}$, Claudia Cristina Auler do Amaral Santos ${ }^{1 *}$}

${ }^{1}$ Programa de Pós-Graduação em Ciência e Tecnologia de Alimentos, Universidade Federal do Tocantins, Palmas, Tocantins, Brasil.

${ }^{2}$ Instituto Federal do Tocantins, Araguaína, Tocantins, Brasil.

*Correspondência: Laboratório de Microbiologia de Alimentos, Universidade Federal do Tocantins, Av. NS 15, 109 Norte, Palmas, Tocantins, Brasil.CEP:77.010-090.e-mail claudiauler@uft.edu.br.

Artigo recebido em -12/11/2019 aprovado em 04/06/2020 publicado em 31/10/2020.

\section{RESUMO}

Os alimentos transgênicos vêm ganhando mais espaço na agricultura brasileira, principalmente na região do Cerrado, que abrange $90 \%$ do território do Estado do Tocantins. O objetivo deste trabalho foi analisar a percepção e aceitabilidade da população tocantinense a respeito dos alimentos transgênicos. Aplicou-se questionários contendo 29 questões para 119 pessoas residentes no Estado. Os questionários foram aplicados nos anos de 2016 a 2018 e analisados pelo método estatístico descritivo. Obteve-se um grau de confiança de 92,9\% e margem de erro de 3,15 pontos percentuais. Observou-se que, $74 \%$ dos entrevistados conheciam a definição de alimentos transgênicos e que $69 \%$ afirmaram que optariam por um alimento não transgênico. No entanto, $74 \%$ afirmam que não leem o rótulo para verificar se o alimento é transgênico. Quanto ao consumo de alimentos transgênicos, 89\% dos entrevistados acreditam que a população consome estes alimentos sem conhecimento prévio. Portanto, nota-se a necessidade de inserção da população nos debates referentes aos transgênicos, bem como uma maior divulgação científica e midiática a respeito do tema para sanar as dúvidas da população sobre assunto.

Palavras-chave: alimentos transgênicos, aceitabilidade, opinião pública.

\section{ABSTRACT}

Transgenic foods have been gaining more space in Brazilian agriculture, especially in the Cerrado region. The objective of this study was to analyze the perception and acceptability of the Tocantins' population regarding transgenic foods. Questionnaires containing 29 questions were applied to 119 people living in Gurupi-TO and other cities of the State. The questionnaires were applied in the years 2016 to 2018 and analyzed by the descriptive statistical method. There was a confidence level of 92.9\% and a margin of error of 3.15 percentage points. It was observed that $74 \%$ of respondents knew the definition of transgenic foods, $69 \%$ said they would opt for a nontransgenic food. However, $74 \%$ said they did not read the label to check if the food was transgenic. Regarding the consumption of transgenic foods, 89\% of respondents believe that the population consumes these foods without prior knowledge. Therefore, it is noted the need for insertion of the population in the debates regarding transgenics, as well as greater cientific and media dissemination to solve population's doubts about the subject.

Keywords: transgenic food, acceptability, public opinion. 


\section{RESUMEN}

Los alimentos transgénicos están ganando más espacio en la agricultura brasileña, especialmente en la región del Cerrado. El objetivo de este estudio fue analizar la percepción y aceptabilidad de la población de Tocantins con respecto a los alimentos transgénicos. Se aplicaron cuestionarios con 29 preguntas a 119 personas que residen en Gurupi-TO y otras ciudades del estado. Los cuestionarios se aplicaron de 2016 a 2018 y se analizaron mediante el método estadístico descriptivo. Se obtuvo un nivel de confianza del 92.9\% y un margen de error de 3.15 puntos porcentuales. Se observó que el 74\% de los encuestados conocía la definición de alimentos transgénicos, el 69\% dijo que optaría por un alimento no transgénico. Sin embargo, el 74\% dice que no lee la etiqueta para verificar si el alimento es transgénico. Con respecto al consumo de alimentos transgénicos, el 89\% de los encuestados cree que la población consume estos alimentos sin conocimiento previo. Por lo tanto, se observa la necesidad de insertar a la población en los debates relacionados con los OGM, así como una mayor difusión científica y mediática sobre el tema para resolver las dudas de la población sobre el tema.

Descriptores: alimentos transgénicos, aceptabilidad, opinión pública.

\section{INTRODUÇÃO}

Os transgênicos são definidos como organismos geneticamente modificados (OGM) de origem vegetal, animal ou microbiana, nos quais o material genético sofreu alterações por meio da engenharia genética pela inserção de sequências exógenas de ácido desoxirribonucleico (ADN). A legislação brasileira define os alimentos transgênicos como sendo todo produto final que contenha $1 \%$ ou mais de ingredientes em sua composição advindos de seres vivos manipulados em laboratório, que tiveram características suprimidas ou super-expressadas com o intuito de obter, por exemplo, maior rendimento, resistência ou valor nutricional, independentemente de sua cadeia produtiva (CIB, 2010).

Ainda a respeito da legislação brasileira sobre alimentos transgênicos, observa-se que estes começaram a ganhar espaço no mercado brasileiro após a edição da Lei ${ }^{\circ}$ 8.974/95, conhecida como $1^{\circ}$ Lei de Biossegurança, revogada pela Lei 11.105/2005. A lei de biossegurança de 2005 “estabelece normas de segurança e mecanismos de fiscalização de atividades que envolvam OGM e seus derivados, e cria o Conselho Nacional de Biossegurança - CTNBio" (BRASIL, 2005).

O Decreto $\mathrm{n}^{\circ} 4.680 / 2003$ regulamenta a rotulagem dos alimentos transgênicos no Brasil. No decreto, o consumidor deve ser informado sobre a presença de transgênicos sempre que o produto apresentar concentração superior a $1 \%$ de OGM, devendo constar no rótulo o símbolo definido pelo Ministério da Justiça, juntamente com as informações: produto transgênico ou contém (nome do ingrediente) transgênico. Em 2016, o Supremo Tribunal Federal estabeleceu que, independentemente do teor, os alimentos que contêm transgênicos devem ser identificados no rótulo (POZZETTI e RODRIGUES, 2018).

Atualmente, os produtos transgênicos aprovados pelo CTNBio para comercialização no Brasil são soja, milho, algodão, feijão, eucalipto e cana-de-açúcar. Alguns desses produtos são alimentos geneticamente modificados (AGM) consumidos diariamente e, devido a sua ampla disponibilidade, é indicado que os consumidores tenham total acesso às informações referentes a eles (POZZETTI e RODRIGUES, 2018; HAKIM et al., 2020).

No ano de 2017, o Brasil cultivou 50,2 milhões de hectares com culturas transgênicas, sendo $67 \%$ para a cultura de soja, $31 \%$ de milho e $2 \%$ de algodão, alcançando o posto de segundo maior produtor mundial de culturas transgênicas. Esse aumento está relacionado com a sua viabilidade 
econômica e ambiental, uma vez que estas culturas são tolerantes às pragas, plantas daninhas e diferentes condições edafoclimáticas, possibilitando maior produtividade (ISAAA, 2018).

As áreas plantadas com culturas geneticamente modificadas têm aumentado de forma global, em 1996 tinha-se 1,7 milhão de hectares e em 2016 atingiu-se 185,1 milhões de hectares, distribuídos em 26 países e diferentes regiões do globo (JAMES, 2016). O Brasil segue a tendência global de aumento das áreas plantadas com culturas geneticamente modificadas. Nesse sentido, o desenvolvimento da agricultura no bioma Cerrado tem um papel central no aumento do cultivo das plantas transgênicas, pois a inserção dos OGM neste bioma ocorre em maior percentual e velocidade do que em outras regiões do Brasil e mesmo em outros países. Outro fator que contribuiu com esta expansão está relacionado com o desenvolvimento do agronegócio nos estados que compõem a nova fronteira agrícola MATOPIBA, que abrange os estados do Maranhão, Tocantins, Piauí e Bahia. Assim, o Cerrado brasileiro tem se destacado como a região de maior cultivo de transgênicos no país, sendo responsável por $63 \%$ da produção (SOUZA et al., 2017, ISAAA, 2018).

Os alimentos transgênicos têm gerado debates calorosos entre membros da comunidade científica. Dentre os que criticam o consumo de alimentos transgênicos, têm-se como principais argumentos: 1) aumento das alergias devido à expressão de novas proteínas e formação de novos compostos resultantes do gene inserido ao alimento; 2) aumento de resistência aos antibióticos, devido à inserção de genes marcadores, oriundos de bactérias, nos alimentos, podendo resultar em microrganismos resistentes; 3) aumento das substâncias tóxicas, devido à introdução de genes que regulam a produção de toxinas utilizadas naturalmente como sistema de defesa pelos organismos; 4) elevação da concentração de agrotóxicos nos alimentos, resultante do fato da maioria dos transgênicos ser resistente à ação dos defensivos agrícolas, o que levou a um aumento destes agrotóxicos e, consequentemente, de seus resíduos nos alimentos; 5) desequilíbrio no ecossistema (IDEC, 2013; AMIN et al. 2014).

Por outro lado, os que defendem o uso dos transgênicos, apontam como principais argumentos: 1) aumento da oferta de alimentos e redução dos preços; 2) alimentos mais nutritivos; 3) possibilidade de redução de substâncias indesejáveis nos alimentos, como, por exemplo, substâncias alergênicas; 4) alimentos com maturação tardia, levando a redução de perdas no campo e no comércio; 5) plantas adaptadas às condições ambientais adversas; 6) Preservação da biodiversidade, visto que não seria necessária a expansão das áreas agricultáveis (CIB, 2009; AMIN et al., 2014).

Hayashi et al. (2012) e Rembischevski e Caldas (2020) afirmaram que o Brasil possui um número limitado de pesquisas a respeito da percepção pública sobre alimentos transgênicos, comparados a países da Europa, Ásia e com os Estados Unidos. Isto evidencia que os debates no país são restritos a certos grupos da sociedade, e tem-se ausência significativa da participação pública.

Os AGM são considerados inovações radicais, sendo recebidos com grandes dúvidas e tornando necessária a sua legitimação. Para a legitimação de inovações tecnológicas é necessário que haja um discurso público, isto é, os cidadãos devem ter condições de acessar as informações, formar julgamentos e articular seus pontos de vista e opiniões. Adicionalmente, a legitimação não é 
estática, tem características dinâmicas, multidimensional e pode mudar ao longo do tempo (JANSMA et al., 2020).

Nesse sentido, a necessidade de estudos da percepção da população brasileira, principalmente da população habitante no Cerrado brasileiro, região com maior produção de transgênicos, sobre as plantas e alimentos transgênicos se faz necessária e urgente. Dessa forma, o presente trabalho tem como objetivo analisar a percepção e aceitabilidade da população tocantinense a respeito dos alimentos transgênicos.

\section{MATERIAIS E MÉTODOS}

O trabalho foi estruturado a partir de uma pesquisa exploratória quantitativa com 119 pessoas, por amostra aleatória, residentes da cidade de Gurupi e outras cidades do Estado do Tocantins. A amostragem utilizada correspondeu a $0,15 \%$ da população residente no Estado, com faixa etária variando de 18 a 51 anos. Os dados foram coletados entre os anos de 2016 e 2019. O questionário continha vinte e nove (29) questões, dentre estas sete (7) questões abordavam a identificação do entrevistado (não obrigatórias), seis (6) sobre dados socioeconômicos e dezesseis (16) questões a respeito dos alimentos transgênicos. $\mathrm{O}$ questionário foi aplicado em diferentes locais, tais como: bares, restaurantes, escolas, universidades, fazendas produtoras de milho e soja transgênicos, bem como por meio digital (Google docs).

Os resultados foram tabulados utilizando-se o programa Excel 2010, e analisados pelo método estatístico descritivo (BATTISTI, 2008).

\section{RESULTADOS E DISCUSSÃO}

Para um grau de confiança de 92,9\% a margem de erro estimada foi de 3,15 pontos percentuais para mais ou para menos sobre os resultados encontrados.

\section{Características socioeconômicas}

De acordo com os questionários aplicados, $60,5 \%$ dos entrevistados são do sexo feminino, $70,3 \%$ são solteiros, $11,8 \%$ moram sozinhos e 48,3\% desenvolvem alguma atividade remunerada. Os entrevistados possuem renda média de 3,8 salários mínimos e $44,5 \%$ possuem o ensino superior completo.

\section{Avaliação da percepção, conhecimento e} aceitabilidade sobre os alimentos transgênicos

Os entrevistados foram indagados sobre a definição de alimentos transgênicos, 74\% disseram conhecer e escreveram a definição (Fig. 1-A). Os termos mais recorrentes nas respostas foram "alimentos geneticamente modificados", "inserção de gene exógeno", “alimentos modificados através das técnicas de engenharia genética" e "alimentos modificados".

Quando questionados sobre o consumo/uso de alimentos transgênicos, 70\% dos entrevistados disseram fazer uso de alimentos transgênicos (Fig. 1B). E quando perguntados se fariam uso de alimentos transgênicos, 76\% disseram que fariam uso (Fig. 1C), sendo que os principais motivos alegados foram: "Não há problema no uso de alimentos transgênicos" e "maior produtividade dos alimentos transgênicos" (Fig. 1-D). Dentre os que responderam que não fariam uso de alimentos transgênicos (11,8\%), os principais motivos apontados foram: "Os alimentos transgênicos são prejudiciais à saúde" e "falta de conhecimento acerca dos alimentos transgênicos" (Fig. 1-E). 
Na pesquisa telefônica realizada em 2016 no Brasil, $73 \%$ dos entrevistados afirmaram já ter consumido alimentos transgênicos, número similar ao encontrado no presente trabalho. Dos 27\% restantes, $59 \%$ responderam que estavam dispostos a experimentar (CIB, 2016).

Segundo Zhang et al. (2018), com relação aos AGM, os principais benefícios percebidos pelos consumidores estão relacionados à questão ambiental, principalmente na redução de insumos químicos, resultando em alimentos mais saudáveis; altos rendimentos e menores custos. Já os riscos percebidos incluem o desconhecimento dos efeitos a longo prazo tanto para a saúde humana quanto para o meio ambiente. O que é compatível com as respostas encontradas no presente trabalho.

Apesar de $76 \%$ dos entrevistados alegarem que fariam uso de alimentos transgênicos e apontarem, em sua maioria, que não vêem problemas no uso, apenas 5\% dos entrevistados afirmaram que caso pudessem escolher optariam por um alimento transgênico (Fig. 1-F). Possivelmente a grande preferência por alimentos não transgênicos está relacionada com a falta de esclarecimentos sobre transgênicos ou com a escassez de informações disponíveis na rotulagem dos alimentos que contém ingredientes trangênicos.

Segundo Amin et al. (2014) a intenção dos consumidores em comprar AGM é uma decisão complexa e não é unidimensional, sendo afetada pelos benefícios recebidos, riscos percebidos, crenças morais, aceitação religiosa, familiaridade percebida, atitudes em relação à rotulagem, regulamentação e até mesmo a confiança no governo e instituições de pesquisa.
Figura 1 - A) Porcentagem de pessoas que conhecem a definição de alimentos transgênicos. B) Porcentagem de pessoas que fazem uso de alimentos transgênicos. C) Porcentagem de pessoas que fariam uso de alimentos transgênicos. D) Motivo pelos quais as pessoas fariam uso de alimentos transgênicos. E) Motivo pelos quais as pessoas não fariam uso de alimentos transgênicos. F) Porcentagem de pessoas que escolheriam alimentos transgênicos e não transgênicos. G) Porcentagem de pessoas contra e a favor da produção de alimentos transgênicos. H) Percentual de pessoas que consideram os alimentos transgênicos seguros para a saúde.

\section{Você conhece a definição de Alimentos} Trangênicos?

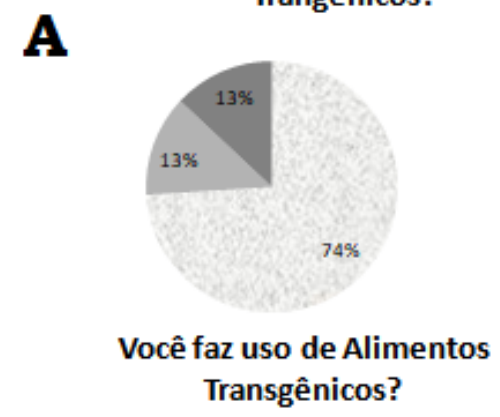

B
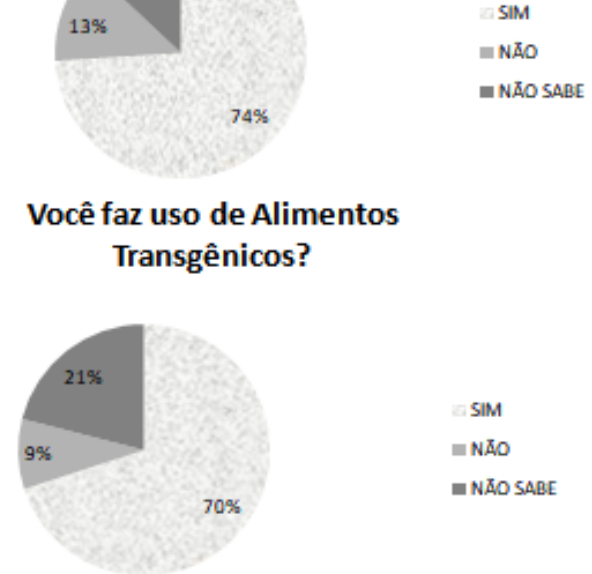

Você faria uso de Alimentos Transgênicos?

$\mathbf{C}$
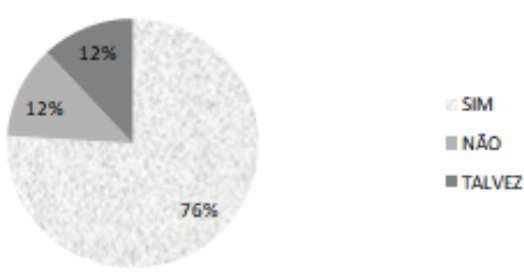

\section{Por quê você faria uso de Alimentos
Transgênicos? \\ Por quê você faria uso de Alimentos
Transgênicos?}

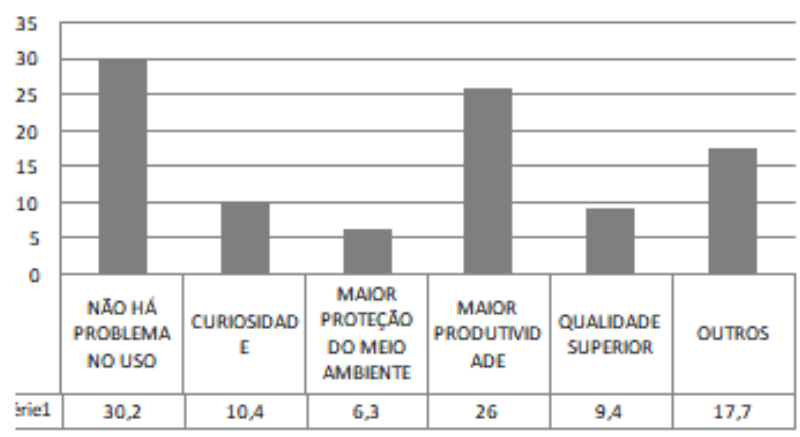



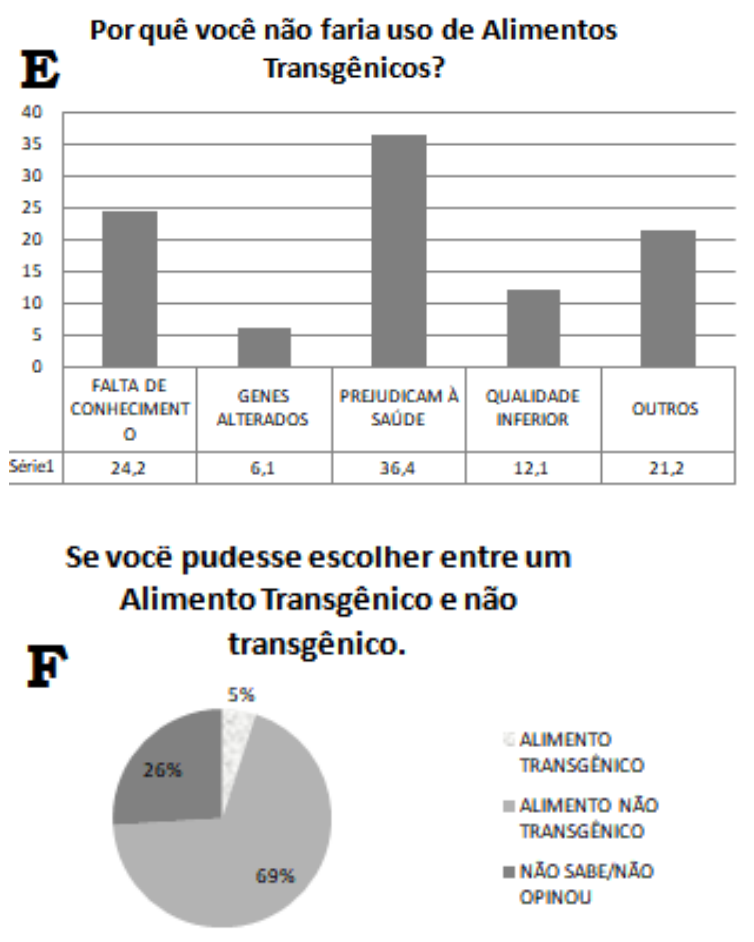

\section{Você é contra a produção de Alimentos Transgênicos?}

G
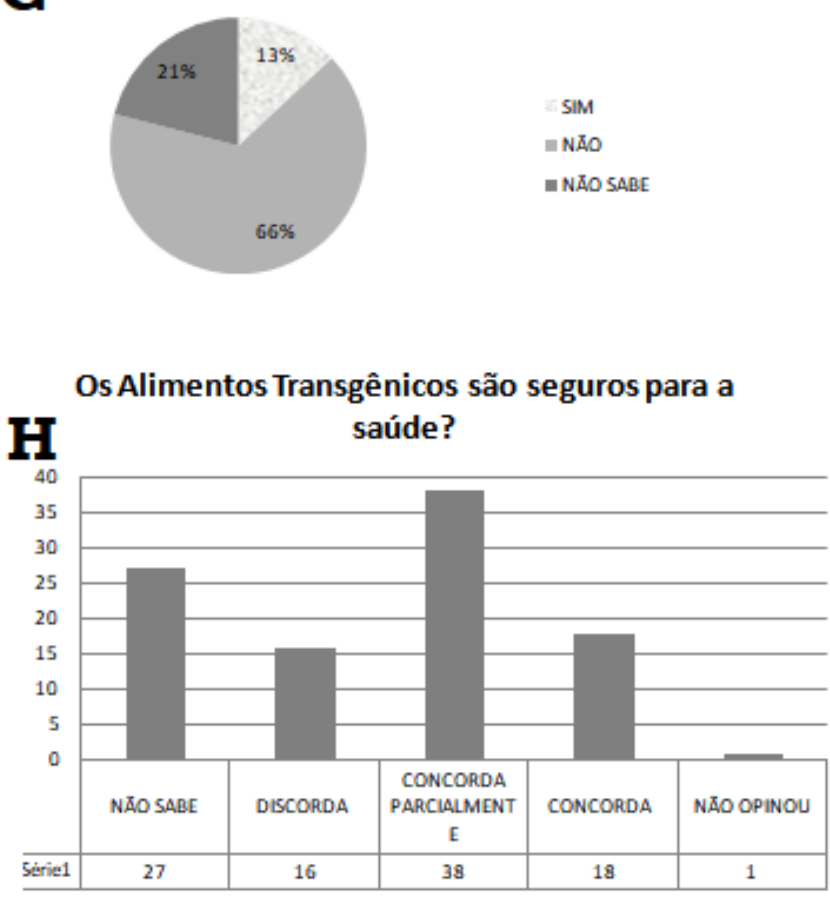

Ao serem indagados sobre a relação dos transgênicos com a saúde, $56 \%$ dos entrevistados concordam ou concordam parcialmente com a afirmativa "Os alimentos transgênicos são seguros para a saúde" (Fig. 1-H). No entanto, 77\% discordam ou não sabem se os alimentos transgênicos são mais saudáveis que os alimentos convencionais ou orgânicos (Fig. 2-A). Esta dúvida sobre os alimentos transgênicos serem mais saudáveis ou não que os alimentos convencionais, também se reflete na preferência pelos alimentos não transgênicos.

Silva et al. (2017) observaram que entre 72 alunos de graduação em nutrição entrevistados, $80,6 \%$ não são favoráveis ao consumo de alimentos transgênicos e 98,6\% afirmaram ter preocupação com os efeitos causados pelos alimentos transgênicos no organismo humano. A população quer consumir alimentos saudáveis, e se aterroriza com a ideia de consumir alimentos produzidos em laboratórios e que contenham genes 'estranhos', e não relacionados à espécie.

O conhecimento sobre o símbolo de alimentos transgênicos $(\uparrow)$ presente nas embalagens também foi objeto de avaliação. Entre os entrevistados, $62 \%$ afirmaram conhecer o símbolo e $62 \%$ também alegaram saber o significado ou já ter visto o símbolo em embalagens de alimentos (Fig. 2B e 2-C). Entretanto, apenas 35\% acreditam que os alimentos transgênicos estão sendo identificados nas embalagens dos produtos (Fig. 2-D). Muitos consumidores $(74 \%$ dos entrevistados $)$ não demonstraram preocupação sobre o consumo de alimentos transgênicos e não verificam os rótulos das embalagens ou não se atentam para a presença de ingredientes transgênicos durante a compra do produto (Fig. 2-E).

Hakim et al (2020) afirmaram que no Brasil a maioria dos consumidores não entende os rótulos dos alimentos, e os consumidores que verificam os rótulos estão mais interessados nas informações relativas ao valor calórico do alimento e não propriamente em sua composição. Marzban et al. (2020) defende que a cultura de ler os rótulos deve 
ser desenvolvida nas famílias, pois esta pode ser uma forma de promover a saúde da comunidade, devendo os centros de saúde, governo e mídia anunciarem a importância da leitura dos rótulos.

No Brasil, a Lei de Biossegurança (Lei ${ }^{\circ}$ 11.105, de 24 de março de 2005), Art. 40 regulamenta que "Os alimentos e ingredientes alimentares destinados ao consumo humano ou animal que contenham ou sejam produzidos a partir de OGM ou derivados deverão conter essas informações em seus rótulos (BRASIL, 2015).” Entretanto, desde 2015, a polêmica a respeito da identificação dos alimentos transgênicos tem aumentado, devido ao Projeto de Lei da Câmara $34 / 2015$ que pretende flexibilizar e alterar a redação do Art. 40 da lei supracitada. Os que são favoráveis à identificação argumentam que o consumidor tem o direito à informação e ao poder de decisão sobre consumir ou não produtos transgênicos. Adicionalmente, alegam que este é um instrumento de rastreabilidade.

Em contrapartida, existe o argumento que apesar de proporcionar informações essenciais a respeito do produto, o símbolo utilizado para identificação é parecido com outros que remetem a placas de trânsito, elementos radioativos e alta voltagem. Desta forma, a parcela da população que tem um pobre conhecimento a respeito de AGM entende que produtos contendo tal emblema deve ser considerados de forma cuidadosa, atenciosa, ou até mesmo vistos como produtos perigosos para a saúde (BRONDANI, 2015).

Amin et al. (2014) afirma que os consumidores tem o direito de saber o que eles estão comendo e bebendo, mas eles não estão em posição de diferenciar claramente os AGM dos produtos que não são geneticamente modificados, a menos que estas informações estejam disponíveis nos rótulos. Assim, as informações fornecidas pelos rótulos são úteis para os consumidores conhecerem os ingredientes e decidirem se devem ou não comprar o produto.

Segundo o CIB (2009) aproximadamente $70 \%$ de todos os alimentos processados contêm pelo menos um ingrediente derivado de soja ou milho, que podem ser transgênicos. Este percentual demonstra como o brasileiro está exposto aos AGM. No entanto, dentre os entrevistados no presente trabalho, $63 \%$ dizem discordar que as informações sobre os transgênicos são repassadas de forma clara e satisfatória e $89 \%$ acreditam que a população consome alimentos transgênicos sem prévio conhecimento (Fig. 2-F e 2-G).

A comunicação acerca dos transgênicos é realizada pelo governo brasileiro de forma não acessível à maior parte da população, devido ao uso de terminologia técnica e especializada, abrindo espaço para que empresas e organizações nãogovernamentais façam seus discursos, sem pluralismo e equilíbrio, defendendo suas próprias perspectivas (HAYASHI et al., 2012).

Segundo Rodríguez-Entrena e SalazarOrdóñez (2013) quando os consumidores se sentem incertos sobre os riscos e benefícios dos AGM, devido à falta de consenso da comunidade científica, eles tendem a colocar a sua confiança nas instituições. Assim, uma política de informação em massa realizada de forma clara, confiável e com rigorosa avaliação dos riscos, poderia aumentar a confiança da população naquela instituição e posteriormente influenciar o consumo de AGM. Adicionalmente, quando a população acessa, por si 
só, informações sobre os AGM o entendimento pode ser comprometido por falta de embasamento técnico.

Zhang et al. (2018) defende que a promoção da tecnologia dos AGM deve ser feita por meio da popularização científica. $\mathrm{O}$ conhecimento sobre transgenia deve receber atenção adequada, pois isso pode ajudar a população a obter uma visão mais abrangente e uma compreensão mais objetiva sobre o assunto. Seu trabalho conclui que a confiança nos institutos de pesquisa poderia aumentar os benefícios percebidos. Assim, tanto cientistas quanto o governo deveriam prestar atenção na comunicação de conhecimento sobre AGM para o público.

Leite (2000) afirma que a mídia possui o papel de divulgar as informações acerca dos transgênicos de forma compreensível, qualificada e contextualizada com a biotecnologia, abordando desde a engenharia genética, transgenia até os resultados finais, incluindo os benefícios e prejuízos, promovendo assim, a mínima condição do público brasileiro participar das discussões de maneira democrática e informada. Por outro lado, Rembischevski e Caldas (2020) indicaram que as pessoas demonstram ter maior confiança nas informações repassadas por cientistas, ainda que via internet, televisão ou revistas, quando comparada às fontes governamentais, ativistas, indústria e meios de comunicação.

Por fim, $61 \%$ dos entrevistados no presente trabalho, ao serem questionados sobre a relação dos transgênicos com o meio ambiente, concordam ou concordam parcialmente com a afirmativa "A cultura de alimentos transgênicos pode trazer prejuízos ao meio ambiente" (Fig. 2-H). E 24\% dos entrevistados discordam da afirmativa "os alimentos transgênicos são a solução para a fome mundial”.
Segundo a Organização das Nações Unidas para Agricultura e Alimentação - FAO apud IDEC (2013) a quantidade de alimentos produzida é suficiente para o abastecimento da população, e temse a capacidade de expansão da produção. Assim, a fome está mais relacionada com as questões socioeconômicas, visto que milhões de pessoas que passam fome não podem pagar pelo alimento, demonstrando que o centro do problema não é a quantidade da produção de alimentos, mas a má distribuição da renda e da terra.

O consumidor representa o final da cadeia de consumo, logo, a aceitação dos AGM por parte dos consumidores afeta diretamente a natureza comercial destes alimentos, o desenvolvimento da tecnologia transgênica e o futuro dos AGM. Ademais, tem sido mostrado que a atitude dos consumidores em relação à tecnologia de transgenia depende do objetivo de sua aplicação, o uso de OGM nas áreas médica, farmacológica e visando aumento nutricional dos alimentos são vistos de forma positiva. Adicionalmente, deve-se ter em mente que a aceitação e reação dos potenciais consumidores são fundamentais para o desenvolvimento de novos produtos alimentícios, assim, estudos como estes que analisam a percepção e aceitação dos consumidores, são fundamentais para avaliação da legitimação dos alimentos GM por parte da população (ZHANG et al. 2018; RODRÍGUEZ-ENTRENA e SALAZARORDÓÑEZ, 2013).

Figura 2 - A) Percentual de pessoas que consideram os alimentos transgênicos mais saudáveis que os convencionais ou orgânicos. B) Porcentagem de pessoas que conhece o símbolo de alimentos transgênicos. C) Porcentagem de pessoas que sabe o que significa ou já viu o símbolo de alimentos transgênicos. D) Percentual de pessoas que considera que os alimentos transgênicos estão sendo identificados nas embalagens. E) Percentual de pessoas que possui o hábito de verificar as embalagens. F) 
Porcentagem de pessoas que consideram que as informações à cerca dos transgênicos são repassadas de forma clara. G) Porcentagem de pessoas que consideram que a população consome transgênicos sem prévio conhecimento. H) Porcentagem de pessoas que considera que a cultura de alimentos transgênicos pode trazer prejuízo ao meio ambiente.

\section{Na sua opinião, os Alimentos Transgênicos são} mais saudáveis que os alimentos convencionais

A ou orgânicos?

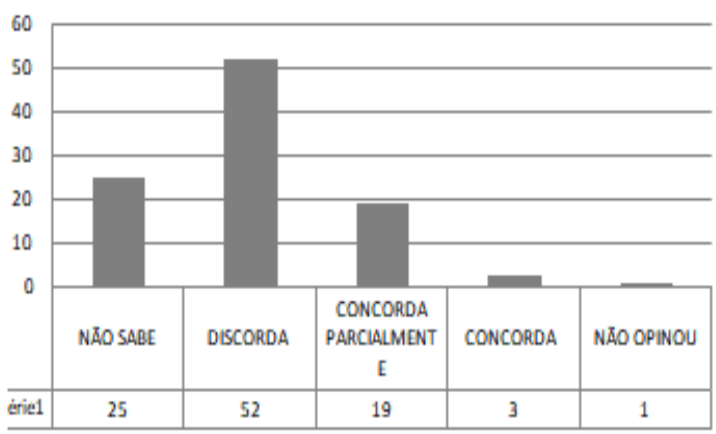

Você conhece o símbolo de Alimentos Transgênicos?

\section{B}

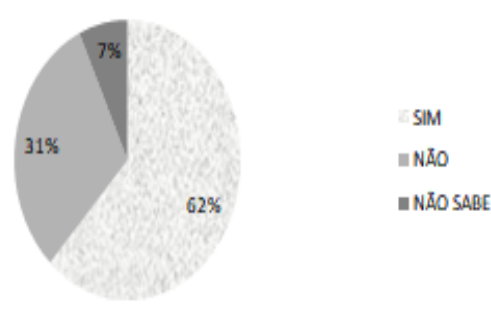

Você sabe o que significa/já viu este símbolo?

$\mathbf{C}$

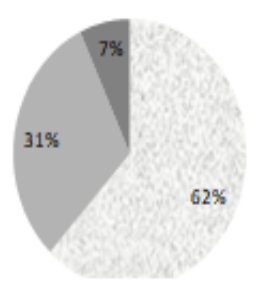

Você acha que os Alimentos Transgênicos estão sendo identificados nas embalagens?

D

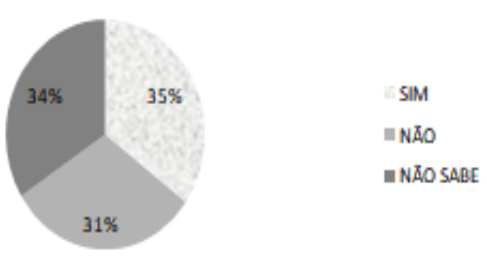

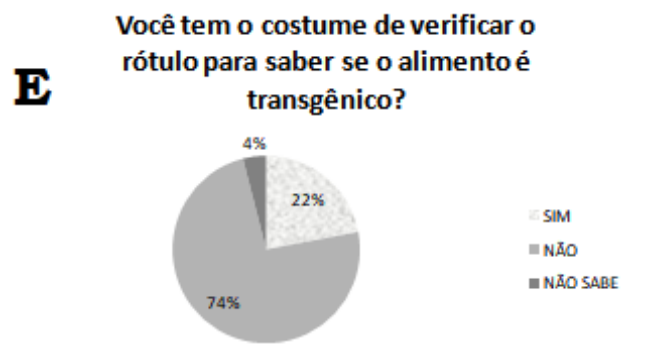
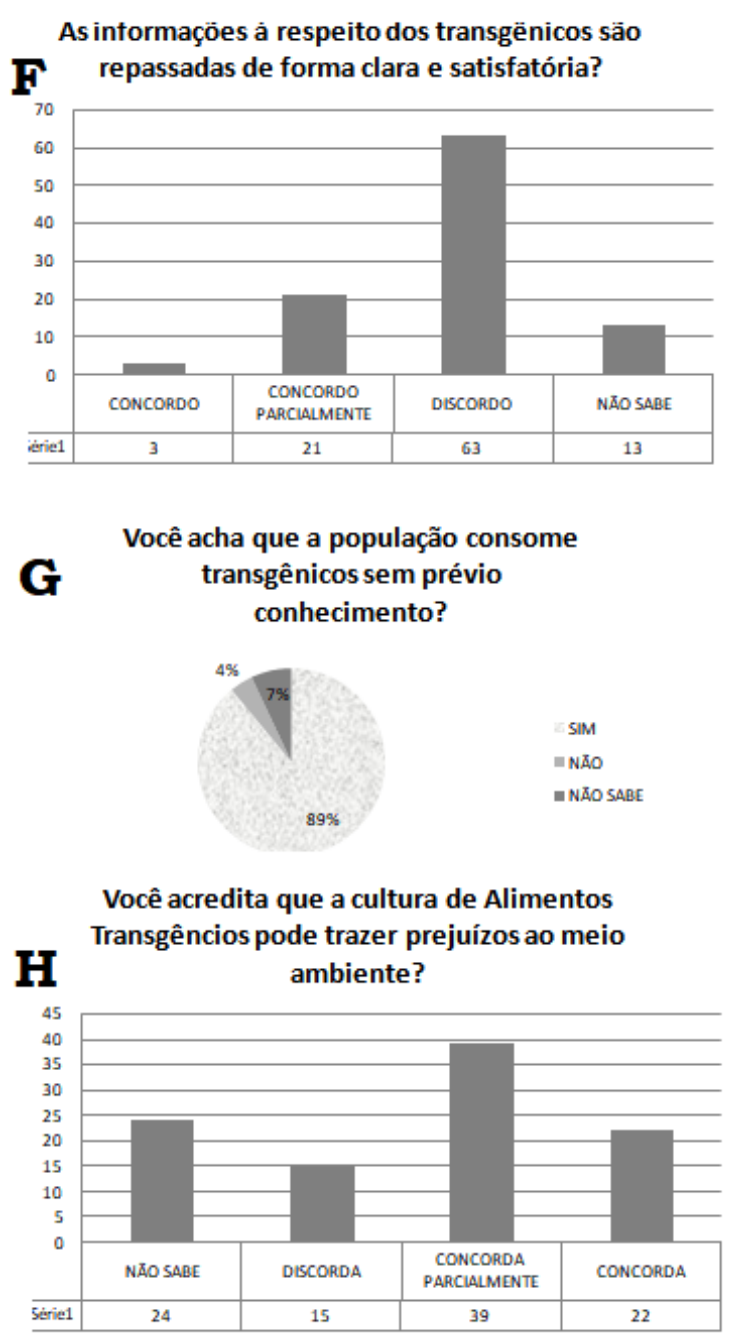

\section{CONCLUSÃO}

As culturas transgênicas estão presentes no cotidiano de todos os brasileiros seja de forma direta ou indireta. No entanto, muitos brasileiros consomem os alimentos transgênicos sem prévio conhecimento e quase um quarto dos entrevistados, no presente trabalho, não sabe se consome alimentos transgênicos, apesar de viverem em uma das regiões com maior expansão da cultura transgênica. Notou-se também a falta de conhecimento e certeza sobre os 
alimentos transgênicos serem seguros e o impacto destes sobre o meio ambiente, bem como a necessidade de maior repasse das informações utilizando termos claros e acessíveis ao público, abordando temáticas que envolvam desde o conceito de biotecnologia, suas metodologias, além dos benefícios e riscos dos alimentos transgênicos.

Todos os autores declararam não haver qualquer potencial conflito de interesses referente a este artigo.

\section{REFERÊNCIAS}

AMIN, L.; AZAD, M. A. K.; AZLAN, N> A. A.; ZULKIFLI, F. Factors influencing stakeholders' attitudes toward cross-kingdom gene transfer in rice. New Genetics and Society. v. 33, n. 4, p. 370-399. 2014.

BATTISTI, I. D. E. Métodos estatísticos. Ijuí: Ed. Unijuí, 2008. - 80 p. - (Coleção educação à distância. Série livro-texto). Disponível em: $<$ http://bibliodigital.unijui.edu.br:8080/xmlui/bitstream /handle/123456789/277/M\%C3\%A9todos\%20estat\% C3\%ADsticos.pdf?sequence $=1>$

BRASIL. LEI No 11.105 , DE 24 DE MARÇO DE 2005. Diário Oficial da República Federativa do Brasil, Brasília, DF, 2005.

BRASIL. LEI No 8.974, DE 5 DE JANEIRO DE 1995. Diário Oficial da República Federativa do Brasil, Brasília, DF, 2005.

BRONDANI, A. Símbolo de transgênico em rótulo traz percepção errada de perigo. 2015. Disponível em:

<https://noticias.uol.com.br/opiniao/coluna/2015/05/ 25/simbolo-de transgenico-em-rotulo-trazpercepcaoerrada-de-perigo.htm>. Acesso: janeiro de 2018.

CIB - Conselho de Informações de Biotecnologia. O que você precisa saber sobre transgênicos. 2009.

CIB - Conselho de Informações de Biotecnologia. Guia do Milho: Tecnologia do campo à mesa, 2010.

CIB- Conselho de Informações de Biotecnologia. Pesquisa Conecta/Ibope. 2016

HAKIM, M. P; ZANETTA, L. D.; OLIVEIRA, J.M. de; CUNHA, D. T. da. The mandatory labeling on genetically modified foods in Brazil: Consumer's knowledge, trust, and risk perception. Food Research International. v. 132. 2020.

HAYASHI， M. C. P. I.; RIGOLIN， C. C. D.; HAYASHI, C. R. M. Transgênicos e sociedade na agenda das pesquisas acadêmicas brasileiras. Política \& Sociedade. v. 11, n 20, 2012.

IDEC - Instituto Brasileiro de Defesa do Consumidor. Transgênicos: Feche a boca e abra os olhos. 12p. 2013.

JAMES, C. Global Status of Commercialized Biotech/GM Crops: 2016. ISAAA Brif 52-2012. NY: ISAAA. 2016.

JANSMA, S. R.; GOSSELT, J. F.; KUIPERS, K.; JONG, M. D. T. de. Technology legitimation in the public discourse: applying the pillars of legitimacy on GM food. Technology Analysis e Strategic Management. v. 32, n. 2, p. 195-207. 2020.

ISAAA - International Service for the Acquisition of Agri-biotech Applications. Situação Global dos Cultivos Transgênicos em 2017: 22 anos de adoção de transgênicos aumentam benefícios econômicos acumulados. 2018.

LEITE, M. Biotecnologias, clones e quimeras sob controle social: missão urgente para a divulgação científica. São Paulo em Perspectiva. vol.14 n.3. São Paulo: 2000.

MARZBAN, A; KARIMI-NAZARI, E.; FARROKHIAN, A.; FARROKHIAN, A.; BARZEGARAN, M. Demographics factors associated with housewives' attitude towards transgenic food products in Yazd. Journal of Nutrition and Food Security. v. 5, n. 2, p. 141-147. 2020.

POZZETTI, V. C.; RODRIGUES, C. B. Alimentos Transgênicos e o princípio da dignidade da pessoa humana. Revista Jurídica (FURB). v. 22, n 48, 2018.

REMBISCHEVSKI, P.; CALDAS, E. D. Risk perception related to food. Food Science and Technology. 2020.

RODRÍGUEZ-ENTRENA, M.; SALAZARORDÓÑEZ, M. Influence of scientific-technical literacy on consumers' behavioural intentions regarding new food. Appetite. v. 60, p. 193-202. 2013. 
SILVA, C. da S.; CARVALHO, C. A. de; BARROQUEIRO, A. T. S.; SOUSA, R. M. L. de; CASTRO, A. C. P. de; SANTOS, A. F. dos. Alimentos transgênicos: conhecimento entre acadêmicos de nutrição. Revista de Investigaçãa Biomédica. v. 9. p. 31-39. 2017.

SOUZA, M. M. O. de; NETO, C. de M. e S.; MELGAREJO, L. Agricultura transgénica e impactos socioambientales: una lectura a partir del Cerrado/Brasil. Agroecologia. v. 12, n. 2, p. 59-70. 2017.

ZHANG, Y.; JING, L.; BAI, Q.; SHAO, W. FENG, Y. YIN, S. ZHANG, M. Application of an integrated framework to examine Chinese consumers' purchase intention toward genetically modified food. Food Quality and Preference. v 65, p. 118-128. 2018. 